\title{
Overview of political economy analysis frameworks in the area of climate governance and key issues to consider
}

Roz Price

Institute of Development Studies

4 June 2021

\section{Question}

- What political economy analysis tools specifically aimed at climate policy available and what are their key features/considerations?

\section{Contents}

1. Summary

2. Political economy analysis and climate change

3. Analytical frameworks and guidance

4. References

The K4D helpdesk service provides brief summaries of current research, evidence, and lessons learned. Helpdesk reports are not rigorous or systematic reviews; they are intended to provide an introduction to the most important evidence related to a research question. They draw on a rapid deskbased review of published literature and consultation with subject specialists. 


\section{Summary}

Despite global recognition of the urgency of climate action and the need to transition to a lowcarbon economy, greenhouse gas emissions continue to rise, and adaptation needs remain urgent. For a number of years there have been calls for greater attention to political economy in tackling climate change and development outcomes (Naess et al., 2015, p. 535; Tanner \& Allouche 2011; Fankhauser et al. 2015). Political economy analysis is important as it can be used to assess the factors that may enable or constrain implementation of climate change policies and actions and sustain political commitment (Worker \& Palmer, 2020). A framework can guide the process of political economy analysis, identifying relevant stakeholders, their incentives and motives, and other structural factors. This rapid review summarises several such frameworks specifically aimed at climate governance issues developed in recent years, some of these also include useful guidance and steps on the implementation of the framework. However, although the literature base is expanding it is still relatively limited (Laws \& Marquette, 2018), especially on the practical application of such frameworks (Worker \& Palmer, 2020; Lamb \& Minx, 2020).

This rapid review draws on both academic and non-governmental organisation literature. The review focuses strictly on the literature around political economy analyses in relation to climate change. It does not explore the history of and rationale for political economy analysis in development in general, nor the accompanying frameworks or operational How To guides (see for example Mcloughlin, 2014; Whaites, 2017). Another K4D helpdesk by Lucas (2019) looking at what factors affect the political will of African governments to address climate change highlights a number of political economy frameworks that may also be useful to draw on.

Key findings:

- Most political economy analysis frameworks for climate governance include structural and institutional elements (i.e. political, social, environmental, and economic conditions that are unlikely to change in the short term) as well as an analysis of actor/stakeholder interests, incentives, and power relations (Naess et al., 2015; Worker \& Palmer, 2020; Lamb \& Minx, 2020).

- Ideas and narratives are also important factors in political economy analysis of climate change, as they can shape worldviews, social and individual identities, and how decisionmakers perceive and respond to the problem (Lamb \& Minx, 2020). Informal and formal rules and norms are also important (Worker \& Palmer, 2020). The role of the international political economy in shaping outcomes at the national and sub-national level may also be considered (Naess et al., 2015).

- Some of the specific (but common) climate issue dimensions in the frameworks identified include: the evidence base; policy framework; awareness and understanding of stakeholders; political commitment; participation and influence of key stakeholders; institutional capacity; finance and investment in climate action (Gogoi \& Harshita, 2018; World Bank, 2021; Worker \& Palmer, 2020).

- Guidance on applying frameworks in practice generally include a variation of: (i) identifying priority objective/change; (ii) observing political challenge; (iii) identifying and convening the most relevant actors; (iv) undertaking the assessment (i.e. assessing the objectives of these actors and the general context - including economic, institutional, environmental, discursive issues); (v) validating findings; (vi) taking action; (vi) evaluating results and monitoring for potential shifts in political economy (Worker \& Palmer, 2020; Gogoi \& Harshita, 2018; Jakob et al., 2020). 
- Most frameworks emphasise the importance of adapting them (and especially the questions asked) to the user's needs and focus. Frameworks are frequently intended to be iterative (not a one-off) so that stakeholders can monitor for changing political economic conditions, they can also allow for comparison of locations (Gogoi \& Harshita, 2018). Clarity from the outset around objectives, the governance issue, available resources, partners and audience of the assessment is also critical (UNDP, 2017).

- As emphasised in a practitioner's guidance note by the Gender \& Development Network, including gender considerations in political economy analysis is critical to gain a more holistic understanding of the causes of poverty, inequality and power dynamics to inform development programming (Haines \& O'Neil, 2018). Given the importance of gender considerations in climate change impacts, action and programming, it can be inferred that gender may also be an important element in political economy analysis of climate governance, however, no frameworks identified in this review explicitly mentioned gender issues.

\section{Political economy analysis and climate change}

\section{Political economy}

The political economy can broadly be defined as "the processes by which ideas, power and resources are conceptualised, negotiated and implemented by different groups at different scales" (Tanner \& Allouche, 2011, p. 2). Whaites (2017, p. 4) highlights that political economy analysis is part of the process of being "politically smart in [development] work... and helps...to peel back the layers of our 'political' context." Practitioners accept that it is critical to conduct a political economy analysis before engaging at the country level in any type of development policy - but many argue that this is even more critical for climate policy as it requires systemic transformations involving an array of different actors, uncertainty, and complexity (Worker, 2017, p. 3).

\section{The importance of political economy for climate governance}

Despite the many compelling reasons for governments to invest in climate action, obstacles to domestic progress on climate goals persist in most countries (Worker \& Palmer, 2020). Although capacity building, domestic and international finance, and transfer of technology are all critical components of effective climate responses, Worker and Palmer $(2020$, p. 3) argue that political

\section{economy factors "shape domestic climate governance and can reveal a much more} nuanced picture of why obstacles... persist."

The complexity of the climate change challenge presents unique governance challenges climate is a global public good and requires collective action by all counties to reduce greenhouse gas emissions, but the long-term benefits will not be felt by today's electorate dampening direct political incentives. Issues include uncertainty, non-linearity and irreversibility of impacts and solutions; procedural and distributive equity concerns; need for unprecedented coordination across sectors and scales; need for durable and credible domestic commitments (Worker \& Palmer, 2020, p. 3). Hallegatte (2019) in a World Bank blog highlighting some key (and often unique) political economy dimensions in relation to climate action largely agrees with these issues, namely ethical and fairness considerations of climate reforms; political feasibility of reforms; the narrative around reforms; and the broader political context within which reforms are proposed. 
Tanner and Allouche (2011, p. 2) contend that political economy approaches to climate change are critical because of:

- The added complexity of interests and actors resulting from the issue's cross-sectoral nature.

- An historical bias towards tackling it as a global issue leading to globally-led governance approaches that may not be sufficiently flexible for national or subnational conditions.

- Problems of rent-seeking and changing incentive structures that are likely to accompany the increase in climate finance and resource transfer.

- An overreliance on a linear apolitical understanding of the policy process and solutions framed through a technical or managerial lens.

- The significant differences in ideological worldviews regarding responding to climate change that affect decisions as to how it should be tackled.

Naess et al. (2015, p. 534) argue that political economy processes are important for linking climate change and national development agendas as they "mediate the winners, losers and potential trade-offs between different goals, and the political and institutional factors which enable or inhibit integration across different policy areas." Jakob et al. (2020, p. 2) emphasise that the underlying political economy needs to be understood in order to identify politically viable entry points for ambitious climate policy - i.e. how economic structure, political institutions and the political environment shape policy outcomes.

For example, in a recent paper Islam et al. (2021) study the role of the political economy factors in the public spending distribution for disaster risk reduction (DRR) funds in Bangladesh. Using a partial least square structural equation model (SEM) approach to evaluate the measurement of latent factors and test the relationships between latent factors they found that political economy factors explain $68 \%$ of the variance in allocations of DRR funding in Bangladesh. In particular, they find that four categories of political economy factors-power and authority, interest and incentives (of influencing stakeholders), institutions, (formal and informal), and (religious) values and ideas-are significantly influential over the distribution of DRR funding across subdistricts of Bangladesh (Islam et al., 2021, p. 2).

\section{Focal points and gaps in the literature}

While much has been written about political economy approaches with regard to development generally and public service delivery specifically, less attention has been given to these approaches in the climate policy and governance literature (Walker, 2017, p. 3). Laws and Marquette (2018, p. 8) undertook a comprehensive review of the evidence on thinking and working politically in development over the past decade. They note that "climate and environmental governance" is one of eight "key sectoral gaps" where there is little direct evidence about thinking and working politically (Laws \& Marquette, 2018, p. 19).

Jakob et al. (2020, p. 2) give a good summary of the history of research on the political economy of climate and energy policy, explaining that it often builds on insights from literature on the political economy of environmental policy. Walker and Palmer (2020, p. 9) in their guide for assessing the political economy of domestic climate change governance, give a brief summary of the previous literature on political economy analysis addressing climate change. They identified that most literature has focused on carbon pricing and the electricity sector and fossil fuel subsidies; or has explored the evidence of effective institutional frameworks, policy 
processes, stakeholder engagement, and political commitment on climate governance; focusing on factors such as government capacity, regulatory ability, strength of the carbon lobby, and the extent of public knowledge of climate change. For example, Fankhauser et al. (2015) studied factors driving climate change legislation using a dataset of climate legislation in 66 national jurisdictions for the period 1990-2013, looking at the following political economy factors: existing legislation, institutions, the business cycle, party-political orientation, electoral cycle and the strength of government (and special interest groups).

Less literature has been published around transportation, energy efficiency, or adaptation; or explored the relative importance of informal bargaining processes, influenced by specific cultural norms or motivated by ideology, in driving climate actions (see Walker \& Palmer, 2020 , p. 9 for further details). Furthermore, there is a lack of evaluations of the application of political economy analyses to the climate policy domain to provide evidence of impact (Walker \& Palmer, 2020, p. 10).

Paterson (2021) argues that climate change has broadly been a blind spot for international political economy being only a relatively marginal concern within international political economy research to date. He argues that international political economy has also "failed to come to grips with two absolutely fundamental shifts in climate politics in the last decade. [Namely] recognition of the social transformation entailed in addressing climate change adequately [and] the increasing recognition of the catastrophic costs of failing to do so" (Paterson, 2021, p. 395). Paterson (2021) argues that international political economy has key conceptual tools and substantive knowledge that it can contribute to understanding these crucial challenges and how to go about pursuing rapid transformation towards decarbonisation.

\section{Analytical frameworks and guidance}

Several frameworks for carrying out political economy analysis of climate governance are summarised below, some of these also include guidance and steps for implementing the framework. Some offer general information about groups of issues that analysts might consider, while others also focus down to the micro or problem-driven level. In all cases it is recommended to consult the specific references for more in-depth information on the frameworks, specific questions to ask and how to apply them.

The literature emphasises that political economy analysis of climate and development trajectories serve as a useful starting point for an informed and grounded discussion of climate governance (Naess et al., 2015, p. 543), however, they are "neither a 'magic bullet' that can be used to change complex realities nor a tool to 'fix' undesirable circumstances" (UNDP, 2017, p. 8)

\section{Jakob et al. (2020)}

Jakob et al. (2020) propose a framework to analyse the political economy of energy and climate policy formulation. With a focus on structural variables and the interplay between different actors, "it builds on the central assumption that policies reflect the objectives of those actors that have the greatest influence in the decision-making process" (Jakob et al., 2020, p. 2). The authors provide a generalised AOC ("Actors, Objectives, Context") political economy framework, which can explore how economic structure, political institutions and the political environment shape policy outcomes, it also enables comparison of country-specific case studies. 
The framework consists of three central elements:

- The most relevant actors that influence policy development, including societal actors and political actors.

- A list of objectives which matter for these actors, acknowledging that energy and climate policies are usually implemented with multiple policy objectives in mind, and these differ across groups (e.g. societal objectives vs political objectives).

- The general context within which policy-making takes place, i.e. determining how a certain objective matters for each actor and how these actors can influence policy formulation.

Applying the framework in practice includes four basic steps (Jakob et al., 2020, p. 1):

i) identifying the societal and political actors most relevant for the formulation, implementation and enforcement of energy and climate policies;

ii) spelling out these actors' underlying objectives;

iii) assessing the economic, institutional, discursive and environmental context which determines how certain objectives matter for certain societal actors; and

iv) analysing the dynamic interactions among these factors leading to aggregate policy outcomes.

Jakob et al. (2020, p. 4) provide examples of societal actors (such as voter groups, unions, civil society, academia etc.) and political actors (such as key ministries and agencies, political parties, regulators etc.), as well as environmental, socio-economic, strategic, and political objectives that the groups may have (such as local air quality, employment and wages, technology transfer, reelection etc.), and contextual factors relevant for formulating climate and energy policy (such as techno-economic, institutional, discursive and environmental). Finally, Jakob et al. (2020) demonstrate how the framework can enable country comparison using three case studies of coal use in India, Indonesia and Vietnam.

\section{Worker \& Palmer (2020) - WRI}

Worker and Palmer (2020) offer an assessment methodology to understand how political economy factors (structural factors, rules and norms, stakeholders and interests, and ideas and narratives) enable or impede climate action in a given country context. Their guide is designed to help multisector national coalitions to grapple with diverse climate governance challenges, including improving coordination across sectors and scales and enabling more transparent monitoring of progress of policy implementation. The guide is being piloted in 2020 and 2021 in Brazil and India with the aim of using feedback to finalise the framework.

The assessment is problem-driven, rather than aimed at providing a broad overview of domestic climate governance. The approach can be contextualised and adapted to suit a multitude of conditions and locations (including choosing questions most relevant to a user's problem), and the authors designed it to be treated more as "an approach to working" rather than a product (Worker \& Palmer, 2020, p. 10). The authors describe it as a governance and political economy assessment, which is also intended to be iterative so that stakeholders can monitor for changing political economic conditions. As the assessment was largely designed for use by domestic civil society coalitions, the authors emphasise the need for other stakeholders to further refine the audience for an assessment to suit their relevant context. Worker and Palmer 
(2020, p. 11) also illustrate the process for how a dynamic political economy for climate action can be assessed (see Figure 1).

Figure 1: Assessing a dynamic political economy for climate action

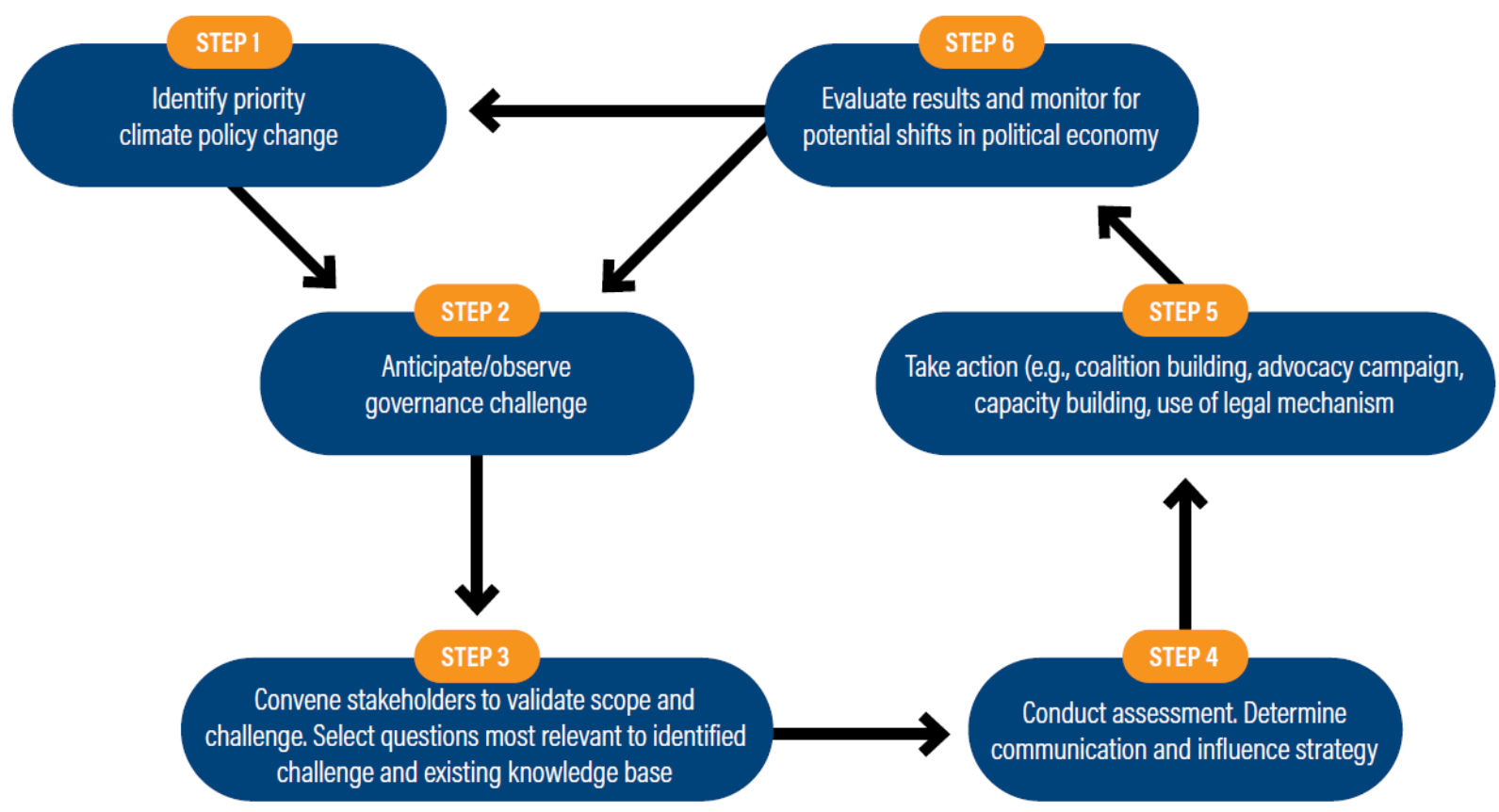

Source: Worker \& Palmer, 2020, p. 11. Reproduced under the Creative Commons Attribution 4.0 International License.

Before the start of the assessment, the guide emphasises the need to define or consider the audience for the assessment outputs (the actors who will use it and who needs to be consulted) and to identify and define the governance challenge in detail (this can help direct focus where technical analysis and engagement have failed to gain operational traction in the past). Once a challenge has been defined and unpacked as much as possible, a cycle of analysis can begin; the four political economy analysis elements considered are (Worker \& Palmer, 2020, p. 16):

- Structural factors that influence the type of climate governance available; these factors are slow to change and most likely will need to be adapted to or worked around to implement climate actions. There are likely to be many structural factors, so it is important to be as selective as possible of those most relevant, do not try to be exhaustive. E.g. questions around climate exposure, economic conditions, demographic trends, level of public debt, levels of inequality, political conditions, territorial sovereignty, cultural and religious conditions, domestic energy resources, civil society, conflict.

- Formal and informal rules and norms, procedures and ways of working that will influence aspects like implementation of the applicable legal framework. These cover formal mandates and structures as well as informal norms based on historical practice, relationships, and power dynamics. E.g. questions around political conditions, transparency, agenda setting, policy enactment, sociocultural norms that inhibit participation, overlapping or conflicting mandates, capacity constraints, information asymmetries, regulatory capture, decision-making procedures, coordination etc. 
- Stakeholders and interests, including individuals and groups who may influence and hold power over the adoption and implementation of climate actions, but also those who are excluded from decision-making. Assessment questions assess key actors and stakeholder groups, their underlying interests, and their incentives in supporting or opposing the climate policy in focus. E.g. questions around co-benefits, power relations, state-society relations, decision-makers, constituencies, power holders, distributional impacts, stakeholder mapping, civic space, external incentive shifts, system shocks etc.

- Ideas that hold power and influence climate change narratives. Ideas and narratives refer to the ideas and framing of the problem and the set of solutions that are commonly deemed to be plausible or desirable. E.g. questions around ideas and ideology, dominant narrative, equity, narrative and communications etc.

Worker and Palmer (2020) provide four annexes with a list of questions for each element, enabling users to pick, choose and adapt the questions to their contexts as needed. They also put forth the following questions as being valuable to reflect on once the initial assessment has been drafted and discussions of it are ongoing (Worker \& Palmer, 2020, p. 20):

- Are there priorities that should be addressed first before other issues can be dealt with?

- What are the risks of confronting potentially deep-seated vested interests directly, and are more circuitous routes available to create change?

- Has unexpected or new information changed objectives or introduced different objectives? If appropriate, does this impact a theory of change or other rationale justifying programming?

- Can actions be taken in the near term that would unlock greater political ambition (by producing policy benefits, creating employment, and thus creating political constituencies)?

\section{Lamb and Minx (2020)}

Lamb and Minx (2020) use a comparative political economy lens to identify national constraints $^{1}$ that actively hinder climate policy progress and limit adoption of deep decarbonisation pathways. Their framework is built on interests, ideas, and institutions as a basic categorisation of political economy constraints on climate policy; they also highlight that international influences is another important factor, although they limit their analysis to just the first three issues due to scope. They explain that:

- Interest-based analysis "recognises that societal changes have material consequences for different actors, such as workers, capitalists, and political agents. These groups actively participate in social and political change, often forming coalitions to lobby and push for common agendas" (Lamb \& Minx, 2020, p. 2).

- Institution-based analysis "usually focuses on the organisation and functions of the nation state... Both the quality of the institutions that carry out these tasks (i.e. their bureaucratic capability) and their different organisational forms (e.g. exposure to veto

\footnotetext{
${ }^{1}$ Lamb and Minx (2020, p. 2) understand "constraints" in their paper as being "social, political and institutional contexts that appear to actively hinder climate policy progress."
} 
players or political cycles) are highly consequential for understanding the constraints to structural change" (Lamb \& Minx, 2020, p. 2).

- Idea-based analysis "argues that the underlying worldviews and ideologies of different actors matter... Beyond the voting public, the ideas of particularly influential actors (e.g. business leaders and politicians) are argued to be highly consequential for social and political change" (Lamb \& Minx, 2020, p. 2).

- International influences "comprise the economic, political and strategic relations between countries... International political norms are a key design element of the Paris Agreement and can strengthen domestic actions. Ideas can also be propagated internationally" (Lamb \& Minx, 2020, p. 2).

The paper identified the following constraints (although there are others too) exposure to fossil fuel extraction activities, supply-side coal dependency, a lack of democratic norms, exposure to corruption, a lack of public climate awareness, and low levels of social trust. Lamb and Minx (2020, p. 12) highlight the strong interrelations and trends between many constraints, which they argue have been under researched in the literature.

\section{Gogoi and Harshita (2018) - Action on Climate Today (ACT) initiative's Climate Governance Assessment}

The Action on Climate Today (ACT) programme was a five year £23 million initiative funded by UK Aid which provides technical assistance to national and sub-national governments in Afghanistan, Bangladesh, India, Nepal and Pakistan. It supports partner governments to mainstream adaptation to climate change in policies, plans, programmes and budgets in order to become more climate resilient (Gogoi \& Harshita, 2018). OPM was the main implementer of the initiative, along with an array of consortium partners.

ACT developed and tested a Climate Governance Assessment approach which allows practitioners to understand the salient features of the political economy and institutional context (opportunities and barriers) for climate change policy in a particular location. This can be used to inform the design of technical assistance programmes, and as part of the process of monitoring and evaluating progress. The Climate Governance Assessment is intended to be light-touch and is designed to be carried out repeatedly, tracking changes over time, and comparing locations (but can also be a one-off) (Gogoi \& Harshita, 2018). In ACT the context analyses were carried out every year and were live documents that fed into a continuous process aimed at monitoring and capturing nuances in the shifting political economy (Cooke, 2017, p. 5).

The specific objectives of the Climate Governance Assessment include (Gogoi \& Harshita, 2018, p. 2):

- To inform the design and delivery of technical assistance climate change programmes through an understanding of the broader institutional and stakeholder environment;

- To monitor broad shifts in an individual government's response to climate change over time, and if relevant also to compare government responses across different locations;

- To facilitate a high-level discussion within a location on the state of progress in tackling climate change. 
The Assessment covers seven dimensions organised within three broad themes: Foundations for action on climate change; Stakeholders for action on climate change; and Mainstreaming of climate change. Together these add up to provide a comprehensive picture of the overall environment for climate change policy-making. The dimensions are (Gogoi \& Harshita, 2018, pp. 3-4):

\section{Foundations for action on climate change:}

1) Evidence Base: Adequacy of the evidence available on climate change in the location, including its relevance, accessibility and the level of uptake. This dimension relates to the availability of research, data and analysis on climate change in the location, and how useful it is to policy-making (and the extent to which it is actually used). It therefore explores both the supply and demand side of evidenced-based decision-making on climate change. The type of information can range from scientific weather data to vulnerability and impact assessments.

2) Policy framework: Effectiveness of the policy-framework for tackling climate change, including adequacy and level of implementation and monitoring and evaluation. This dimension relates to whether there is an overarching cross-sectoral policy, strategy, legal framework or action plan for tackling climate change, and whether this has been implemented, and monitored and evaluated. This is important for understanding the level of political will, as well as specific government priorities for tackling climate change.

\section{Stakeholders for action on climate change:}

3) Awareness and understanding: Level of awareness and understanding of key stakeholders on tackling climate change. This dimension relates to the extent to which different stakeholders both within and outside government understand the cause and impact of climate change in the location. This is important for identifying points of confusion, as well as the language and narrative used for talking about climate change in the location.

4) Political commitment: Level of political commitment, in terms of priority and significance accorded by key stakeholders to tackling climate change. This dimension relates to the extent to which different stakeholders both within and outside government consider climate change a priority issue for the location. This includes the extent to which political leaders have voluntarily taken action to address climate change, rather than responded to an external pressure.

5) Participation and influence: Level of participation and influence of key stakeholders on the decision-making process for tackling climate change. This dimension relates to the extent to which different stakeholders have the potential to participate in and influence decisions related to tackling climate change, and if so, whether they act on this potential and actually engage in and influence the decision-making process. This is important for identifying those individuals who can champion change within the system.

\section{Mainstreaming of climate change:}

6) Institutional capacity: Institutional capacity for mainstreaming climate change into development planning, including institutional mechanisms for coordination across government and between different levels of government. This dimension relates to the wider institutional set-up for mainstreaming climate change within the regular planning and budgetary process in the location. For those locations with a cross-sectoral policy- 
framework, this also relates to the capacity for implementing it within sectoral ministries or departments.

7) Finance and investment: Investment in mainstreaming climate change into development planning, including availability of public and private sector funding and international climate finance. This dimension relates to the amount of public and private sector funding, and international climate finance, which is currently being invested in tackling climate change. This is another indicator of the level of political will, as well as the availability of resources to fund mainstreaming of climate change.

The Assessment is primarily a qualitative exercise and relies heavily on the opinions and views of those involved in the assessment process; it needs at least 3 weeks, but can be spread over a few months (Gogoi \& Harshita, 2018, p. 4). Gogoi and Harshita (2018) provide a How To note on the Climate Governance Assessment, giving an in-depth break down of the tool, its different dimensions and detailed guidance for undertaking each step of the Assessment process, it is recommended that note is consulted for further insights. Figure 2 below provides a summary of the general Assessment process, but Gogoi and Harshita (2018) underline that the process is flexible, and each step can be adapted to suit specific needs (see Gogoi \& Harshita, 2018 for more detailed information on each step).

See: Figure 2: Climate Governance Assessment process steps, Source: Gogoi \& Harshita, 2018, p. 4, https://www.opml.co.uk/files/Publications/8617-action-on-climate-today-act/contextassessment-methodology.pdf?noredirect=1

In the ACT programme a common and streamlined methodology was used at each location with the assessment mostly being qualitative and focused around a key informant discussion of at least 10 stakeholders from outside government, but who work closely with the government on climate change issues (Cooke, 2017, p. 5). The opinions gathered were then validated and refined against the results of bilateral discussions with government officials, third party reports and documentation. This approach does not aim to provide an objective analysis, but uses expert opinion to explore some of the 'difficult to quantify' dimensions, such as political will and capacity (Cooke, 2017, p. 5). This political analysis was combined with continuous monitoring of the shifting political environment by the ACT team leaders and their staff at the local level, often on an informal, day-to-day basis. Cooke (2017) emphasises the importance that political analysis be embedded in everyday routine practice in an iterative way, aiming to bring 'thinking and acting politically' into everyday work to encourage reporting on political constraints as they emerge.

\section{Naess et al. (2015)}

Naess et al. (2015) deploy a political economy framework to investigate low carbon energy in Kenya and carbon forestry in Mozambique, exploring intersections between climate policy and development goals. The framework integrates three common strands in understanding the underlying dynamics that determine the outcomes of policy and practice (Naess et al., 2015, p. 536):

- Politics and interests - this emphasises the interactions of state and civil society, and different interest groups, social segments or classes. This is the core of classic political economy analysis. 
- Narratives and evidence - this examines the histories and practices linked to shifting discourses, and how these shape and guide policy problems and courses of action.

- Actors and institutions - this gives primacy to the roles and agency (or capacity to make a difference) of individual actors, and relates to the scope for human or social agency to overcome structural constraints and to change institutions and policy processes.

To structure the case studies they focus on three aspects in particular (Naess et al., 2015, p. 536):

- Context: In each case study they establish the policy challenge and characterise the recent historical and institutional context most pertinent to understanding and addressing it. This helps to map out the broad landscape of power within which interventions aiming at integrated climate and development policy goals have to operate.

- Competition and conflict: They then analyse the actors, institutions and power relations that shape the resolution of policy processes on particular terms, favouring some actors and outcomes over others.

- Consequences: Lastly, they examine the outcomes that result or are likely to result from the patterns of competition, conflict and collaboration described above. This helps to identify who the winners and losers are, how the benefits and disadvantages of current patterns of resource use are distributed and how trade-offs have been resolved and could be resolved otherwise.

From the application of the framework to the case studies to understand complex change processes, Naess et al. (2015, p. 543) draw out three lessons:

1. Issues must be understood in view of long standing debates and struggles over resources between institutions and actors, which affect how and why they engage with climate change policy.

2. Attempts to work with or against the grain of politics in a particular setting require an appreciation of the social and political networks and relations of power which will determine how the trade-offs inherent to climate change and development goals are worked through and on whose behalf.

3. The role of the international political economy, in the form of global economic institutions, corporations and donors, critically shapes outcomes at the national and sub-national level albeit in ways mediated by the differential policy autonomy that governments have.

\section{World Bank (2021) - Climate Change Institutional Assessment (CCIA)}

Although not strictly a political economy analysis, the World Bank (2021) recently released a guide on how to undertake their Climate Change Institutional Assessment (CCIA). The $\mathrm{CCIA}$ identifies the strengths and weaknesses of the institutional framework for addressing climate change governance challenges; it is aimed at officials and agencies with leading roles in climate change policy, and inter-ministerial climate change bodies.

The CCIA comprises five pillars (World Bank, 2021, p. 2): 
1. Organisation: Assesses the regulatory framework for climate change policy, the functional mandates of government agencies, coordination arrangements, and the technical capacity to support climate change policy.

2. Planning: Evaluates systems for climate change risk and vulnerability assessments, strategies, and plans and the regulatory framework for the climate change planning and policy process. Other elements include long-term and medium-term strategies, development planning, monitoring, reporting and verification obligations.

3. Public Finance: Considers the integration of climate strategies, plans, and policies in fiscal and public financial management (PFM) practices and the mobilization of resources for climate action. Other elements include public investment and asset management, and public procurement.

4. Subnational Governments and State-Owned Enterprises: Examines the treatment of climate change in the intergovernmental system and in the management of state-owned enterprises (SOES), the capacity of subnational governments (SNGs), and incentives for climate action. Elements include strategic and land use planning, functional assignment, coordination and capacity, subnational climate finance.

5. Accountability: Reviews transparency and engagement mechanisms for civil society, the private sector, and other stakeholders and the roles of expert advisory and oversight institutions. Elements include access to climate information, stakeholder engagement, independent expert advice, legislative body, audit, judicial review.

The CCIA focuses on crosscutting public institutions and mechanisms for engaging with nongovernment stakeholders and complements other analytical processes. The outcome is a prioritised list of recommendations for action. The CCIA is flexible and can be conducted as a stand-alone assessment or as part of other diagnostics. It can be used to inform the design of institutional reforms for Nationally Determined Contributions (NDC) and climate strategies, or by donors to inform the design of institutional reforms for budget support and technical assistance; however, it does not undertake an in-depth review of climate policies (World Bank, 2021, p. 2).

\section{UNDP (2017) - Institutional and Context Analysis (ICA)}

The Institutional and Context Analysis (ICA) was first launched by UNDP as an approach to support country-level programming in 2012, largely based on by political economy analysis methodologies developed by the World Bank and DFID. The current ICA builds on lessons learned from the application of the ICA approach to country programming as well as on international experience with the use of similar analytical frameworks and is presented in the Guidance Note as a tool under Acceleration in the MAPS - Mainstreaming, Acceleration and Policy Support ${ }^{2}$ context (UNDP, 2017, p. 5). Acceleration is aimed at helping to identify possible bottlenecks in policy implementation and address the complex interrelations underlying sustainable development. Thus, the Guidance Note defines ICA as "an analysis that focuses on political and institutional factors in a given country and how these may have a positive or negative impact on the implementation of policies for the achievement of the Sustainable Development Goals" (including climate change) (UNDP, 2017, p. 6). The ICA is an inter-disciplinary political economy framework; it is intended as a tool to help understand

${ }^{2}$ MAPS is the United Nations Development Group (UNDG) common approach to supporting the 2030 Agenda. 
political economy dimensions of development, but at a 'meso' or 'micro' level, and looking at a specific development problem (UNDP, 2017, p. 15). A typical ICA has a duration of 4-6 weeks (including desk review and a 1-2 week mission), depending on how detailed it is, geographical location etc. It is only "as good as its follow-up" and if it is a one-off exercise then it likely will not be followed up or particularly useful (UNDP, 2017, p. 17).

The steps in an ICA include:

1. Define the scope of the analysis.

2. Map out and analyse formal and informal rules and institutions. Example questions: How are responsibilities distributed between the national and sub-national levels in this area? How are responsibilities distributed between public, private or public-private bodies active in this area? Are the relevant laws/policies being implemented? Is the proposed policy likely to challenge stakeholders or informal rules directly or indirectly? Is it likely to change the rules of the game, in terms of depriving certain groups or individuals of privileges they currently enjoy? etc.

3. Stakeholder analysis. Issues include stakeholder mapping, understanding stakeholders' incentives and constraints, and how to engage with different types of stakeholders and foster coalitions for change.

4. Design engagement strategies and assign responsibility for implementation. 


\section{References}

Cooke, K. (2017). Reflections on using political economy analysis in OPM's Action on Climate Today Programme, Oxford: Oxford Policy Management.

https://www.opml.co.uk/files/Publications/8617-action-on-climate-today-act/using-pea-inact.pdf?noredirect=1

Fankhauser, S., Gennaioli, C., \& Collins, M. (2015). The political economy of passing climate change legislation: Evidence from a survey. Global Environmental Change, 35, 52-61. https://doi.org/10.1016/j.gloenvcha.2015.08.008

Gogoi, E. \& Harshita, B. (2018) ACT Climate Governance Assessment: How to note. Oxford: OPM. https://www.opml.co.uk/files/Publications/8617-action-on-climate-todayact/context-assessment-methodology.pdf?noredirect=1

Haines, R \& O'Neil, T. (2018). Putting gender in political economy analysis: Why it matters and how to do it. Practitioners' Guidance Note, The Women's Participation and Leadership Working Group, Gender \& Development Network. https://gadnetwork.org/gadnnews/2018/5/9/putting-gender-in-political-economy-analysis-why-it-matters-and-how-todo-it

Hallegatte, S. (2019, 5 December). Listening to the streets: the political economy of climate policy. World Bank Blogs. [Blog] https://blogs.worldbank.org/climatechange/listeningstreets-political-economy-climate-policy

Islam, S., Zobair, K.M., Chu, C., Smart, J.C.R. \& Alam, M.S. (2021). 'Do Political Economy Factors Influence Funding Allocations for Disaster Risk Reduction?' Journal of Risk and Financial Management, 14(85). https://doi.org/10.3390/jrfm14020085

Jakob, M., Flachsland, C., Steckel, J. C., \& Urpelainen, J. (2020). Actors, objectives, context: A framework of the political economy of energy and climate policy applied to India, Indonesia, and Vietnam. Energy Research \& Social Science, 70, 101775. https://www.sciencedirect.com/science/article/pii/S2214629620303509

Lamb, W. F., \& Minx, J. C. (2020). The political economy of national climate policy: Architectures of constraint and a typology of countries. Energy Research \& Social Science, 64, 101429. https://doi.org/10.1016/j.erss.2020.101429

Laws, E., \& Marquette, H. (2018). Thinking and working politically: reviewing the evidence on the integration of politics into development practice over the past decade. Birmingham, UK: University of Birmingham. https://twpcommunity.org/wpcontent/uploads/2018/04/Thinking-and-working-politically-reviewing-the-evidence.pdf

Lucas, B. (2019). Political will of African governments to address climate change. K4D Helpdesk Report 701. Brighton, UK: Institute of Development Studies. https://opendocs.ids.ac.uk/opendocs/handle/20.500.12413/14813

Mcloughlin, C. (2014). Political economy analysis: Topic guide (2nd ed.) Birmingham, UK: GSDRC, University of Birmingham. https://gsdrc.org/topic-guides/political-economyanalysis/ 
Naess, L. O., Newell, P., Newsham, A., Phillips, J., Quan, J., \& Tanner, T. (2015). Climate policy meets national development contexts: Insights from Kenya and Mozambique. Global Environmental Change, 35, 534-544. http://dx.doi.org/10.1016/j.gloenvcha.2015.08.015

Paterson, M. (2021). Climate change and international political economy: between collapse and transformation, Review of International Political Economy, 28:2, 394-405. DOI: 10.1080/09692290.2020.1830829

Tanner, T., \& Allouche, J. (2011). Towards a new political economy of climate change and development. IDS bulletin, 42(3), 1-14. https://doi.org/10.1111/j.1759-5436.2011.00217.x

UNDP. (2017). Guidance Note: Institutional and Context Analysis for the Sustainable Development Goals. UNDP. https://www.sdgphilanthropy.org/system/files/201901/Guidance\%20Note\%3A\%20Institutional\%20and\%20Context\%20Analysis\%20for\%20t he\%20Sustainable\%20Development\%20Goals.pdf

Whaites, A. (2017). The Beginner's Guide to Political Economy Analysis (PEA). National School of Government International (NSGI), UK AID.

https://assets.publishing.service.gov.uk/government/uploads/system/uploads/attachment _data/file/766478/The_Beginner_s_Guide_to_PEA.pdf

Worker, J. \& Palmer, N. (2020). "A Guide to Assessing the Political Economy of Domestic Climate Change Governance." Working Paper. Washington, DC: World Resources Institute. doi.org/10.46830/wriwp.18.00047

Worker, J. (2017). National climate change governance: Topic guide. Birmingham, UK: GSDRC, University of Birmingham. https://gsdrc.org/wp-content/uploads/2016/08/NatCCGov.pdf

World Bank. (2021). Climate Change Institutional Assessment. Equitable Growth, Finance and Institutions Notes, Washington, DC: World Bank. https://openknowledge.worldbank.org/handle/10986/35438

\section{Acknowledgements}

We thank the following experts who voluntarily provided suggestions for relevant literature or other advice to the author to support the preparation of this report. The content of the report does not necessarily reflect the opinions of any of the experts consulted.

- Lars Otto Naess, Institute of Development Studies

\section{Suggested citation}

Price, R.A. (2021). Overview of political economy analysis frameworks in the area of climate governance and key issues to consider. K4D Helpdesk Report 1014. Institute of Development Studies. DOI: 10.19088/K4D.2021.088 


\section{About this report}

This report is based on six days of desk-based research. The K4D research helpdesk provides rapid syntheses of a selection of recent relevant literature and international expert thinking in response to specific questions relating to international development. For any enquiries, contact helpdesk@k4d.info.

K4D services are provided by a consortium of leading organisations working in international development, led by the Institute of Development Studies (IDS), with the Education Development Trust, Itad, University of Leeds Nuffield Centre for International Health and Development, Liverpool School of Tropical Medicine (LSTM), University of Birmingham International Development Department (IDD) and the University of Manchester Humanitarian and Conflict Response Institute (HCRI).

This report was prepared for the UK Government's Foreign, Commonwealth \& Development Office (FCDO) and its partners in support of pro-poor programmes. Except where otherwise stated, it is licensed for non-commercial purposes under the terms of the Open Government Licence v3.0. K4D cannot be held responsible for errors or any consequences arising from the use of information contained in this report. Any views and opinions expressed do not necessarily reflect those of FCDO, K4D or any other contributing organisation.

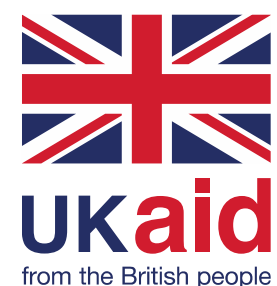

(C) Crown copyright 2021. 